OPEN ACCESS

Edited by:

Xiaomin $\mathrm{Li}$

Fudan University, China

Reviewed by:

Xiaoji Xie,

Nanjing Tech University, China

Yong Fan,

Fudan University, China

*Correspondence:

Lining Sun

Insun@shu.edu.cn

Specialty section:

This article was submitted to Nanoscience,

a section of the journal

Frontiers in Chemistry

Received: 26 September 2020 Accepted: 09 November 2020 Published: 08 December 2020

Citation:

Pei S, Ge X and Sun L (2020) Metal Ions Doping for Boosting Luminescence of Lanthanide-Doped Nanocrystals. Front. Chem. 8:610481.

doi: 10.3389/fchem.2020.610481

\section{Metal lons Doping for Boosting Luminescence of Lanthanide-Doped Nanocrystals}

\author{
Shihao Pei, Xiaoqian Ge and Lining Sun* \\ Research Center of Nano Science and Technology, College of Sciences, Shanghai University, Shanghai, China
}

With the developing need for luminous materials with better performance, lanthanide-doped nanocrystals have been widely studied for their unique luminescence properties such as their narrow bandwidth emission, excellent chemical stability, and photostability, adjustable emission color, high signal-to-background ratio, deeper tissue penetration with less photo-damage, and low toxicity, etc., which triggered enthusiasm for research on the broad applications of lanthanide-doped nanocrystals in bioimaging, anti-counterfeiting, biosensing, and cancer diagnosis and treatment. Considerable progress has been made in the past few decades, but low upconversion luminescence efficiency has been a hindrance in achieving further progress. It is necessary to summarize the recently relevant literature and find solutions to improve the efficiency. The latest experimental and theoretical studies related to the deliberate design of rare earth luminescent nanocrystals have, however, shown the development of metal ion-doped approaches to enhance the luminescent intensity. Host lattice manipulation can enhance the luminescence through increasing the asymmetry, which improves the probability of electric dipole transition; and the energy transfer modulation offers a reduced cross-relaxation pathway to improve the efficiency of the energy transfer. Based on the mechanisms of host lattice manipulation and energy transfer modulation, a wide range of enhancements at all wavelengths or even within a particular wavelength have been accomplished with an enhancement of up to a hundred times. In this mini review, we present the strategy of metal ion-doped lanthanide nanocrystals to cope with the issue of enhancing luminescence, overview the advantages and tricky challenges in boosting the luminescence, and provide a potential trend of future study in this field.

Keywords: metal ion doping, host lattice manipulation, energy transfer modulation, lanthanide doped nanocrystals, enhanced luminescence

\section{INTRODUCTION}

Fluorescence imaging has attracted increasing attention for observing a vast number of biological structures due to high sensitivity, superior subcellular resolution, and ultrafast real-time imaging (Weissleder and Pittet, 2008). The frequent fluorescent probes that are exploited in imaging include fluorescent proteins (Ben et al., 2006), metal complexes (Zhao et al., 2010, 2011), organic fluorescent dyes (Terai and Nagano, 2008; Beija et al., 2009; Yuan et al., 2013), and semiconductor quantum dots (Zhou J. et al., 2015; Xu et al., 2016; Hildebrandt et al., 2017). However, most of them are excited 
by ultraviolet or visible light, which leads to significant background noise and low penetration depth (Fan and Zhang, 2019). Moreover, high-energy ultraviolet or visible light may cause cell apoptosis or tissue damage.

Alternatively, lanthanide-doped nanocrystals (LDNCs) are excited by near infrared (NIR) light, such as 980 or $808 \mathrm{~nm}$, offering lower scattering coefficients and autofluorescence, and a higher penetration depth (Kobayashi et al., 2009; Yuan et al., 2013). Besides the NIR light excitation, the LDNCs also have several spectroscopic benefits: (1) a sharp emission band with a full-width at half-maximum (FWHM) $<10 \mathrm{~nm}$ and a long decay lifetime ( $\mu$ s to ms) (Bünzli, 2010; Fan et al., 2018); (2) hundreds of nanometers of anti-Stokes or Stokes shift (upconversion or downshifting the luminescence process) (Su et al., 2017); and (3) excellent photo and chemical stability (no photoblinking or photobleaching) (Su et al., 2017). Although LDNCs possess such excellent spectroscopic characteristics, the major drawback of LDNCs is their low quantum yield (QY) due to the low extinction coefficient of lanthanide ions in the NIR region and energy lost during multi non-radiative electronic transitions (Wang et al., 2011). In recent years, researchers have been devoted to solving this drawback, such as constructing core-shell structures (Chen et al., 2015; Zhuo et al., 2017) and anchoring NIR dyes on the surface of nanocrystals (Wu X. et al., 2016; Hazra et al., 2018). Among countless methods for improving the QY (Zhang et al., 2010; Yin et al., 2016), metal ion doping is the simplest since it is carried out in fewer modulation steps (Niu et al., 2012; Ding et al., 2015), and it only weakly changes the shape of the LDNCs. Moreover, metal ion doping can integrate with other methods to simultaneously improve the QY of LDNCs.

Here, we aim to provide a summary regarding the recent progress in metal ion doping for improving the QY of LDNCs. In this mini review, we first discuss the two mechanisms of metal ion doping: host lattice manipulation and energy transfer modulation. More cases outlining how to carry out metal ion doping are also included. Finally, we discuss the challenges and future applications of LDNCs with metal ion doping. We also hope that this mini review can serve as a guide for researchers who are involved in metal ion doping for LDNCs study.

\section{MECHANISMS OF LUMINESCENCE ENHANCEMENT BY DOPING METAL IONS}

\section{Host Lattice Manipulation}

The optical characteristic of lanthanide NPs is derived from its intrinsic trivalent lanthanide ions $\left(\mathrm{Ln}^{3+}\right)$, which are considered the most stable state of lanthanides. $\mathrm{Ln}^{3+}$ ions have the configuration of $[\mathrm{Xe}] 4 \mathrm{f}^{\mathrm{n}}, n=0-14$, and the electronic transitions in the $4 \mathrm{f}$ orbital are diverse, resulting in the emissions from these electronic transitions being distributed within wide wavelengths (Hatanaka and Yabushita, 2014). There are several decisive factors for the energy levels of free $\mathrm{Ln}^{3+}$ ions in their $4 \mathrm{f}$ orbitals, like the Coulombic interaction and the spin-orbit coupling between $\mathrm{f}$ electrons (Han et al., 2014), which are rather sensitive to minor changes of the host lattice.

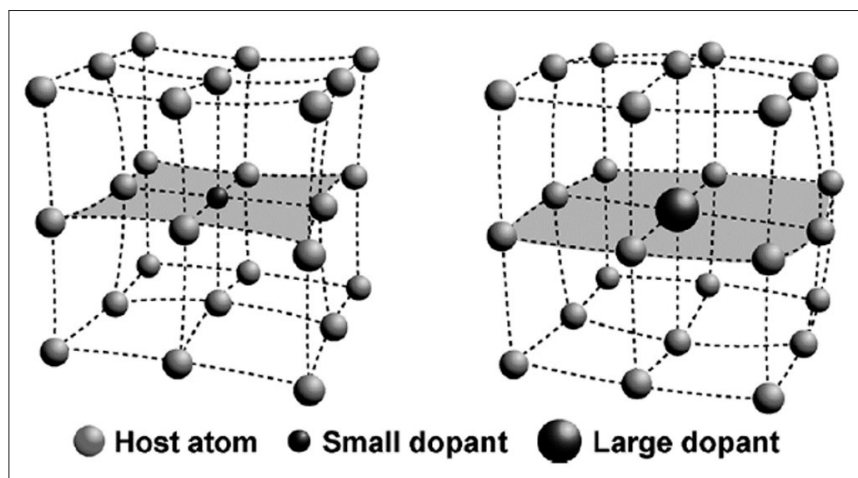

FIGURE 1 | The contraction (left) and expansion (right) of the host lattice after adopting a small or large dopant. This figure was adopted from Han et al. (2014).

As for metal ion doping, the lanthanide ions sites in the host lattice are replaced, and the host lattice may be distorted and its interplanar spacing will change due to the radius difference between the metal ions and lanthanide ions. When using a high metal ion concentration, the lattice gap will be filled with metal ions (Dou and Zhang, 2011). Thus, the asymmetric host lattice affects the environment of inner lanthanide ions, leading to the increase of lanthanide luminescence. For example, the probability of the electric dipole transition can be dramatically increased by the asymmetric crystal field.

By disrupting the symmetric environment of the central ions, the mixing of the opposite-parity configurations can break the Laporte selection rule (Harris and Bertolucci, 1978), which was applied to a centrosymmetric system where the electric dipole transitions are barely allowed. Therefore, reasonably, with the introduction of the asymmetric crystal field, the probability of the electric dipole transition can be dramatically increased. Then the luminescence intensity of the nanocrystal can be enhanced by increasing the asymmetry around the lanthanides.

For doping metal ions with different radii, the host lattice may undergo different changes. The host lattice will shrink after doping metal ions with a small radius, whereas metal ions with a large radius lead to the expansion of the host lattice (Figure 1). The changing of the host lattice dramatically alters the splitting of the crystal field and the coordination environment, resulting in the increase of the probability of the electric dipole transition, and then enhancing the luminescence intensity (Han et al., 2014).

\section{Energy Transfer Modulation}

All fluorescence light usually follows the well-known Stokes' law which illustrates that the energy level of the excitation photons is higher than the emitted photons, whereas the doping of lanthanides or transition metal ions can violate this principle under a properly powered excitation, generating antiStokes emission.

The anti-Stokes process is a multi-ions process. In principle, the premise of energy transfer is that the absorption and emission are not in the same center, and it can take place without 
charge transport. Moreover, energy transfer can be divided into radiative, non-radiative, resonant, and phonon-assisted energy transfer (Hatanaka and Yabushita, 2014). The energy transfer process contains two steps, whose natural efficiencies are $\leq 1$. Therefore, finding a way to reduce the unwanted cross-relaxation type of energy transfer and converting this energy into a certain wavelength of emission improves the luminescent intensity by energy transfer modulation. Higher doping of activator ions could be a potential candidate that can lead to the enhancement of luminescence, whereas the quenching effect has been a hindrance in achieving this goal. Therefore, owing to the macroscopic diffusion process, the overall efficiency enhancement brought about by energy transfer can only be obtained through spatial averaging (Auzel, 2004).

The metal ion doping in the LDNCs can modulate the energy transfer between the doped metal ions and other lanthanide ions in the host lattice (Han et al., 2014). This modulation depends on controlling the re-distribution of all ions in the host lattice (Auzel, 2004). Specifically, the distance between activators and sensitizers in the host lattice is changed by doping metal ions, neither too long nor too short, which is crucial for boosting the luminescence intensity. For example, the increase of doping ions can facilitate the harmful cross-relaxation between dopants due to their proximity (Qin et al., 2019). For another method of manipulating the ion distribution reported by Qin et al. (2014), they indicate that, in a particular host lattice, the lanthanide ions tend to segregate in the form of chains or clusters upon host cation substitution. As a result, the five-photon upconversion (Wang et al., 2014) and single band emission (Wu M. et al., 2016) can be achieved.

Moreover, the re-distribution of activators decreases the probability of cross-relaxation, and a photon energy depletion pathway arises from activators or between an activator and a defect in the host lattice. Thus, the lower cross-relaxation probability allows us to use a higher activator concentration so that the luminescence intensity enhances, which is also called breaking the concentration quenching effect (Auzel, 2004). Most importantly, the d-d electronic transition of metal ions may be involved in the energy transfer between activators and sensitizers in the host lattice, and it is an effective energy transfer pathway (Han et al., 2014). So, if the energy transfer pathway produced by the doped transition metal ions works out, the upconversion luminescence of the LDNCs should be enhanced.

Unlike the normal f-f transition, the emission intensity of the hypersensitive transition will change dramatically even if its surrounding environment has a tiny change. By changing the environment around the rare-earth ions, a hypersensitive transition can be produced. The doping of different kinds of metal ions should be an easy way to alter the environment around the rare-earth ions. It is well-known that the upconversion luminescence intensity of lanthanide ions is mainly dependent on electronic transition probabilities (Hatanaka and Yabushita, 2014). Owing to their unique properties, increasing the probability of hypersensitive transition will be beneficial in increasing the luminescence intensity of LDNCs.

\section{CASES OF METAL ION-DOPED LANTHANIDE NANOCRYSTALS AND THEIR BIOAPPLICATIONS}

\section{$\mathrm{Li}^{+}$Ion Doping}

The radius of metal ions has a significant impact on the luminescent intensity of LDNCs through changing the symmetry of its host lattice around the lanthanide ions (Figures 2A-D). This impact was verified by doping ions, including $\mathrm{Li}^{+}, \mathrm{Ca}^{2+}$ (Zhao et al., 2020), and $\mathrm{Bi}^{3+}$ ions (Jiang et al., 2012; Niu et al., 2012) into the host lattice. For example, the $\mathrm{Li}^{+}$ion owns the smallest alkali ionic radius, around 0.73-1.06 $\AA$, enabling a high doped concentration in the host lattice (Dou and Zhang, 2011). Chen et al. reported that $5 \%$ of $\mathrm{Li}^{+}$-doped $\mathrm{Y}_{2} \mathrm{O}_{3}: \mathrm{Yb}, \mathrm{Er}$ nanocrystals (NCs) (Chen et al., 2008) show 25 times and 8 times more luminescent intensity enhancements for the green and red emissions, respectively, in comparison with $\mathrm{Y}_{2} \mathrm{O}_{3}: \mathrm{Yb}, \mathrm{Er}$ $\mathrm{NCs}$ without $\mathrm{Li}^{+}$doping. The similar luminescence enhancement was also found in $\mathrm{Li}^{+}$-doped $\mathrm{ZrO}_{2}$ (Liu et al., 2011), and $\mathrm{NaGd}\left(\mathrm{MoO}_{4}\right)_{2}$ (Chen et al., 2020) host lattices. However, the symmetry of the host lattice may undergo different changes when using different synthesized temperatures. For example, at $1,073 \mathrm{~K}$, the $\mathrm{Er}^{3+}-\mathrm{Li}^{+}$co-doped $\mathrm{TiO}_{2} \mathrm{NCs}$ showed an accelerated phase transition from anatase to rutile when increasing the $\mathrm{Li}^{+}$concentration, resulting in the decrease of luminescence intensity. At $1,273 \mathrm{~K}$, the phase structure of $\mathrm{Er}^{3+}-\mathrm{Li}^{+}$co-doped $\mathrm{TiO}_{2} \mathrm{NCs}$ was unchanged no matter what the $\mathrm{Li}^{+}$concentration was, yet the crystal field symmetry decreased, resulting in significantly enhanced emission intensities (Cao et al., 2010).

Besides, it was reported that the doping of $\mathrm{Li}^{+}$can achieve the enhancement of luminescent intensity at a particular wavelength range. Yin et al. (2012) reported that $\mathrm{GdF}_{3}: \mathrm{Er}, \mathrm{Yb}$ co-doped with $\mathrm{Li}^{+}$, with a color-tuned emission from yellow to red, showed a slightly decreased green emission whereas the red emission had a dramatic increase of up to 8-fold. And the red light displayed a deep penetration depth, which was used for the in vivo imaging (Figure 2E). This phenomenon can be attributed to the energy back transfer process initiated by the doping of $\mathrm{Li}^{+}$ions.

As for host lattice materials, a fluoride-based host lattice is an excellent candidate for co-doped $\mathrm{Li}^{+}$ions. In 2017, $\mathrm{Hu}$ et al. (2017) reported 18 times and 7 times luminescence enhancement of 478 and $804 \mathrm{~nm}$ emissions of $\mathrm{NaLuF}_{4}: \mathrm{Yb}, \mathrm{Tm}$ with a $7 \% \mathrm{Li}^{+}$-doped concentration, respectively. Zhao C. et al. (2013) developed 8 times luminescence enhancement of the upconversion emission of $452 \mathrm{~nm}$ in $\mathrm{NaYF}_{4}: \mathrm{Yb}, \mathrm{Tm} \mathrm{NCs}$ with a $\mathrm{Li}^{+}$concentration of $7 \%$. Furthermore, Ding et al. (2015) studied different kinds of lanthanide ions co-doped with $\mathrm{Li}^{+}$in an $\mathrm{NaGdF}_{4}$ host lattice crystal, which all afford large enhancement in lanthanide luminescence intensity. Dou and Zhang (2011) have concluded the possible substitution sites of $\mathrm{Li}^{+}$-doped and $\mathrm{K}^{+}$-doped ions in an $\mathrm{NaYF}_{4}$ host lattice, respectively, in which the substitution and the interstitial occupation both exist, only related to the concentration of the doping ion. As shown in Figures 2F,G, with an increase in $\mathrm{Li}^{+}$concentration from 40 to $60 \%$, the morphology of nanocrystals changed from nanorods to nanospheres, and 

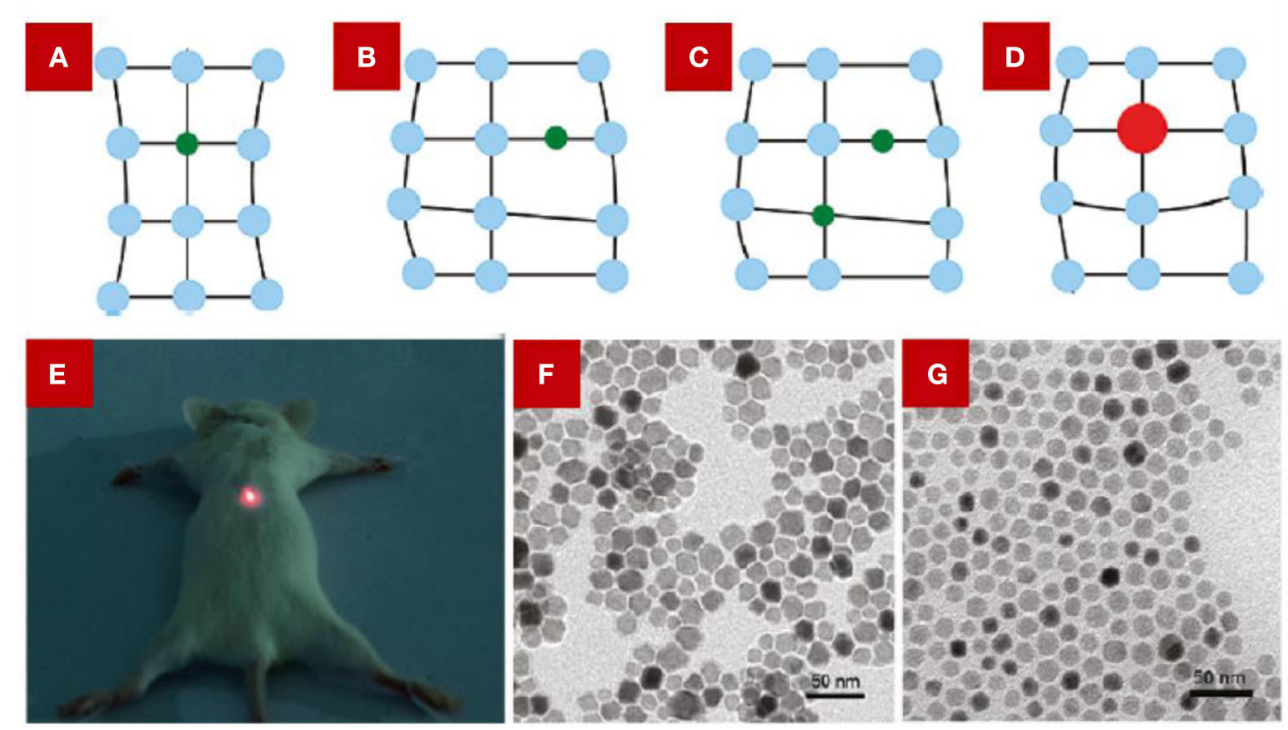

FIGURE 2 | The scheme shows the possible ways of doping alkali ions in the host lattice of NaYF 4 . (A) Substitution by a small atom. (B) Interstitial occupation by a small atom. (C) Combination of substitution and interstitial occupation. (D) Substitution by a large atom. From Dou and Zhang (2011). (E) The digital image of an anesthetized mouse under the irradiation of a $980 \mathrm{~nm}$ laser. The mouse was injected the $\mathrm{GdF}_{3}$ :Er, $\mathrm{Yb}$ co-doped with $\mathrm{Li}^{+}$dispersion in the back muscle. (E) was adopted from Yin et al. (2012). And (F,G) are TEM images of $\mathrm{Na}_{(1-\mathrm{x})} \mathrm{Li}_{\mathbf{x}} \mathrm{YF}_{4}$ :Er,Yb NCs. (F) x $=40$ mol\%, (G) x=60 mol\%. (F,G) were adopted from Dou and Zhang (2011).

the phase changed from a hexagonal to a cubic phase as well.

What also needs to be considered is the doping efficiency. Wang et al. studied the doping efficiency of $\mathrm{Li}^{+}$in the $\mathrm{KSc}_{2} \mathrm{~F}_{7}$ host lattice, they indicated that $\mathrm{Li}^{+}$doping efficiency is highly related to its initial concentration (Wang et al., 2017). In general, the actual amount of $\mathrm{Li}^{+}$doped into the host lattice is much lower than its initial concentration.

\section{$\mathrm{Fe}^{3+}$ ion Doping}

Similar to $\mathrm{Li}^{+}, \mathrm{Fe}^{3+}$ doping can also alter the symmetry of the host lattice in LDNCs. In an $\mathrm{NaGdF}_{4}$ host lattice, the $\mathrm{Fe}^{3+}$ doping can meet the goal of boosting the luminescent intensity through altering the asymmetry around the lanthanide ions, and this enhancement is a general improvement for all emission ranges around the luminescence center (Ramasamy et al., 2013). Interestingly, the synthesis method of LDNCs influences the crystal structure, and thus affects the symmetry of the host lattice after doping $\mathrm{Fe}^{3+}$. For example, the hexagonal $\mathrm{NaYF}_{4}$ became tetragonal after increasing the $\mathrm{Fe}^{3+}$ concentration when using a hydrothermal method (Tang et al., 2015). However, the crystal structure of the $\mathrm{NaGdF}_{4}$ host lattice is inert to the thermal decomposition even using a high $\mathrm{Fe}^{3+}$ concentration (Figures 3A,B) (Ramasamy et al., 2013). In addition, the doping of $\mathrm{Fe}^{3+}$ can tailor the crystal field environment of $\mathrm{Er}^{3+}$, which helps the hypersensitive transition, leading to the enhancement of upconversion luminescence (Ramasamy et al., 2013).

Besides, the $\mathrm{Yb}^{3+}-\mathrm{Fe}^{3+}$ dimer was formed in the host lattice, which can be applied to modulate the energy transfer between activators and sensitizers, in particular modulating the energy transfer for the red emission (Tang et al., 2015; Du et al., 2019). For the $\mathrm{Fe}^{3+}$-doped $\mathrm{NaYF}_{4}: \mathrm{Yb}, \mathrm{Er}$ NCs (Figure 3C), the existence of $\mathrm{a} \mathrm{Yb}^{3+}-\mathrm{Fe}^{3+}$ dimer can be deduced from the much lower $n$ value ( $n$ represents the number of phonons process) of green/red emissions of the hydrothermal method-synthesized LDNCs compared with the traditional two-phonon process. The energy level of $\left.\right|^{2} \mathrm{~F}_{7 / 2},{ }^{4} \mathrm{~T}_{1 \mathrm{~g}}>$ of the $\mathrm{Yb}^{3+}-\mathrm{Fe}^{3+}$ dimer receives the photon energy from the energy level of ${ }^{2} \mathrm{H}_{11 / 2}$ of $\mathrm{Er}^{3+}$, and the received photon energy can partially return to the energy level of ${ }^{4} \mathrm{~F}_{7 / 2}$ and ${ }^{4} \mathrm{~S}_{3 / 2}$ of $\mathrm{Er}^{3+}$. After the photon energy in ${ }^{4} \mathrm{~F}_{7 / 2}$ and ${ }^{4} \mathrm{~S}_{3 / 2}$ relaxes to the ${ }^{4} \mathrm{~F}_{9 / 2}$ level, the probability of the electronic transition between ${ }^{4} \mathrm{~F}_{9 / 2}$ and ${ }^{4} \mathrm{I}_{15 / 2}$ of $\mathrm{Er}^{3+}$ increases, which contributes to increase the intensity of the red emission of $\mathrm{Er}^{3+}$. Meanwhile, the green/red emission of $\mathrm{Fe}^{3+}$-doped NCs synthesized by the thermal decomposition method has been confirmed as a two-phonon process (Ramasamy et al., 2013), which has less correlation with the $\mathrm{Fe}^{3+}$ concentration. However, the $\mathrm{Fe}^{3+}$-doped NCs synthesized by the hydrothermal method show the potential relationship between the concentration of $\mathrm{Fe}^{3+}$ and the phonon process, suggesting that the formation of the $\mathrm{Yb}^{3+}-\mathrm{Fe}^{3+}$ dimer might be related to the synthesis method of the LDNCs. Furthermore, the $\mathrm{Fe}^{3+}$-doped NCs were used in the upconversion luminescence (UCL) imaging of $\mathrm{HeLa}$ cells (Figures 3D-F), which demonstrates a potential application in bioimaging.

\section{$\mathrm{Mn}^{2+}$ ion Doping}

It was discovered that the $\mathrm{Mn}^{2+}$ ion can also modulate the energy transfer between activators and sensitizers in the host lattice of LDNCs (Wang J. et al., 2011). With the example of $\mathrm{Mn}^{2+}$-doped 

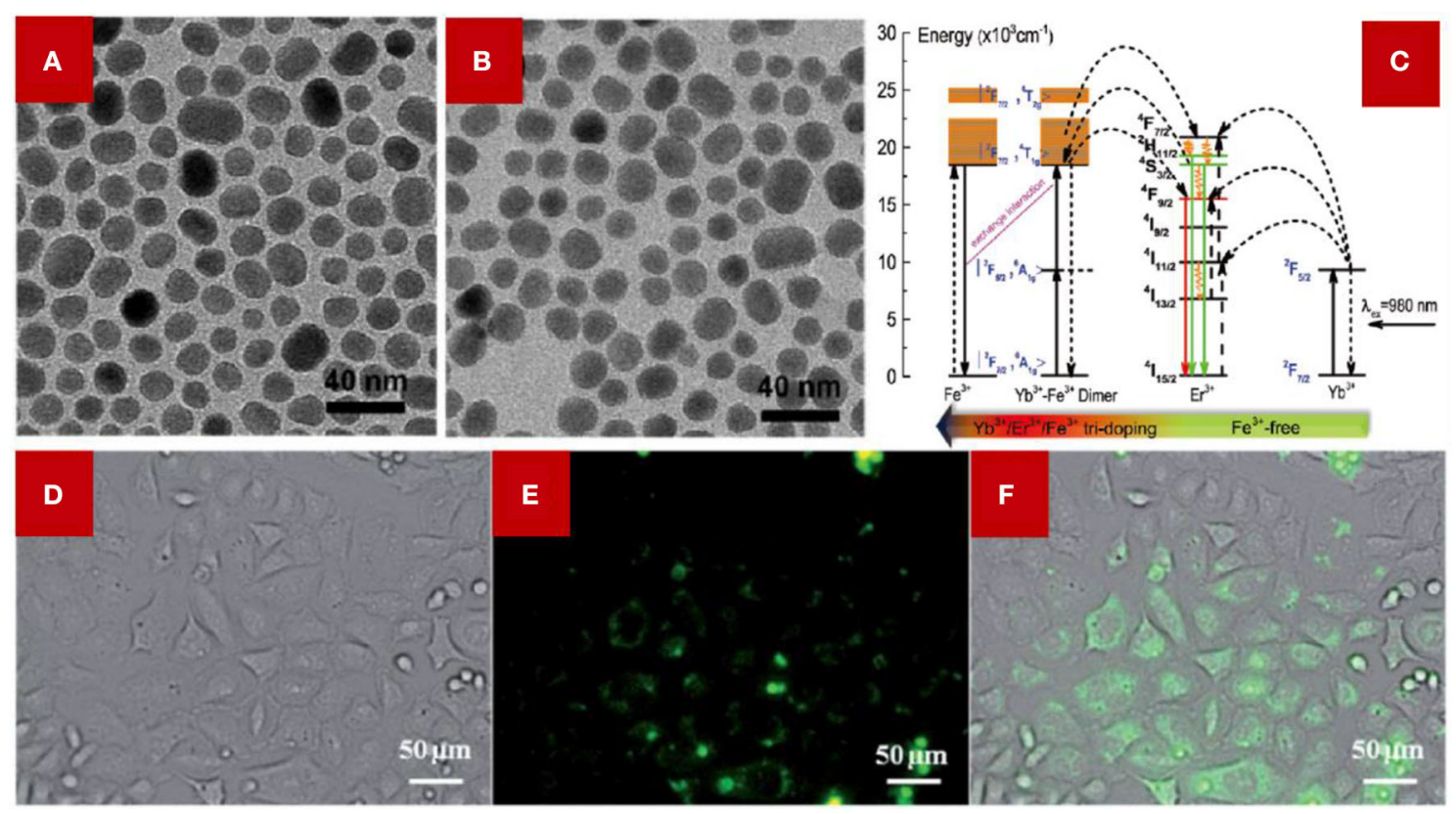

FIGURE 3 | TEM images of $\mathrm{NaGdF}_{4}$ :Yb,Er,Fe NCs, (A) 0 mol \% Fe ${ }^{3+}$ doping; (B) 30 mol\% Fe ${ }^{3+}$. Adopted from Ramasamy et al. (2013) (C) Illustration of the proposed energy transfer mechanism of $\mathrm{Fe}^{3+}$ co-doped NaYF $4: Y b, E r ~ N C s$ and NaYF 4 :Yb,Er NCs without Fe ${ }^{3+}$ doped. The color arrow in the below indicates the $\mathrm{Fe}^{3+}$ content varied from 0 to 5-40 mol\%. (C) was adopted from Tang et al. (2015); (D-F) NaGdF 4 :Yb,Er,Fe NCs were used for cellular luminescence imaging. (D) The bright field image of HeLa cells incubated with $\mathrm{NaGdF}_{4}: \mathrm{Yb}, \mathrm{Er}$,Fe NCs. (E) The confocal fluorescence image. The HeLa cells were irradiated with a $980 \mathrm{~nm}$ laser. (F) The merging of (D,E). (D,E) were adopted from Ramasamy et al. (2013).

$\mathrm{NaYF}_{4}: \mathrm{Yb} / \mathrm{Er} \mathrm{NCs}$ (Figures 4A,B), the single red emission can be ascribed to the energy transfer from the ${ }^{2} \mathrm{H}_{9 / 2}$ and ${ }^{4} \mathrm{~S}_{3 / 2}$ energy level of $\mathrm{Er}^{3+}$ to the ${ }^{4} \mathrm{~T}_{1}$ energy level of $\mathrm{Mn}^{2+}$, and then the received photon energy in ${ }^{4} \mathrm{~T}_{1}$ transfers back to the ${ }^{4} \mathrm{~F}_{9 / 2}$ energy level of $\mathrm{Er}^{3+}$, which contributes to the red emission of the $\mathrm{NaYF}_{4}: \mathrm{Yb} / \mathrm{Er} \mathrm{NCs}\left({ }^{4} \mathrm{~F}_{9 / 2} \rightarrow{ }^{4} \mathrm{I}_{15 / 2}\right)$ (Tian et al., 2012). The single red emission phenomenon was also confirmed in the $\mathrm{Mn}^{2+}$. doped $\mathrm{NaYF}_{4}$ (Zeng et al., 2014), $\mathrm{NaGdF}_{4}$ (Li et al., 2015), and $\mathrm{NaLuF}_{4}$ (Zeng et al., 2014) host lattices.

Owing to the sensitivity of $\mathrm{Mn}^{2+}$ to the ligand field (Zhou et al., 2018), the energy level state of ${ }^{4} \mathrm{~T}_{1}$ is different in different host lattices, such as $\mathrm{NaGdF}_{4}$ or $\mathrm{LiYF}_{4}$. The higher energy level of ${ }^{4} \mathrm{~T}_{1}$ of $\mathrm{Mn}^{2+}$ in an $\mathrm{LiYF}_{4}$ host lattice matches the green luminescence energy level of ${ }^{4} \mathrm{~S}_{3 / 2}$ of $\mathrm{Er}^{3+}$, and the lower energy level of ${ }^{4} \mathrm{~T}_{1}$ of $\mathrm{Mn}^{2+}$ matches better with the red emission energy level of ${ }^{4} \mathrm{~F}_{9 / 2}$ of $\mathrm{Er}^{3+}$ in the $\mathrm{NaGdF}_{4}$ host lattice, and thus explains that the ratio of green and red emission intensity is not a fixed value (Zhou et al., 2018). Thus, the sensitivity of $\mathrm{Mn}^{2+}$ endorses the potential application of $\mathrm{Mn}^{2+}$ in modulating the energy transfer of different lanthanide ions. Moreover, $\mathrm{Mn}^{2+}$ doping can induce the phase transition of the $\mathrm{NaYF}_{4}$ host lattice, from hexagonal to cubic, when using the hydrothermal method. In spite of the fact that the cubic $\mathrm{NaYF}_{4}$ lattice was confirmed to have a lower luminescence efficiency than the hexagonal one, the asymmetry of the $\mathrm{NaYF}_{4}$ changed because the $\mathrm{Y}^{3+}$ sites were replaced by $\mathrm{Mn}^{2+}$ ions with a smaller radius, then the luminescence intensity increased. Fig. 4 a shows the cubic phase of $\mathrm{NaYF}_{4}: \mathrm{Yb}$,Er doped with $30 \mathrm{~mol} \% \mathrm{Mn}^{2+}$ ions. The red emission has a higher signal-to-noise ratio and lower autofluorescence than the green emission. Therefore, lanthanide NCs with a single red emission are beneficial for in vivo small-animal imaging (Figures 4C-E).

\section{RARE EARTH IONS DOPING}

Besides activators and sensitizers, doping other rare earth ions into a host lattice is also an efficient way to boost the luminescence intensity. For example, $\mathrm{Sc}^{3+}$ has been widely studied because it has the smallest radius among all the rare earth ions, meaning it can be easily doped into a host lattice. With a similar host lattice manipulation mechanism, the symmetry of an $\mathrm{NaYF}_{4}$ host lattice was broken when doping $\mathrm{Sc}^{3+}$ into $\mathrm{NaYF}_{4}: \mathrm{Er}, \mathrm{Yb} \mathrm{NCs}$; thus, the overall emission intensity of $\mathrm{NaYF}_{4}: \mathrm{Er}, \mathrm{Yb}$ NCs showed a 2-fold enhancement when doped with $10 \%$ mol Sc$^{3+}$ (Huang et al., 2010).

And other lanthanide ions, for example, activator ions with a high doping concentration such as $\mathrm{Er}^{3+}, \mathrm{Tm}^{3+}$, and $\mathrm{Ho}^{3+}$, have been used to accept photon energy from sensitizer ions. However, the high concentration activator ions lead to the concentration quenching effect that is generated from cross-relaxation between activator ions. Zhao J. et al. (2013) built a combined system with micro-structured optical fiber (Figure 5A), which confines the high-power laser into a micrometer-sized circle. They demonstrated that a 70 -fold enhanced luminescence intensity was obtained with high concentration doping of $8 \% \mathrm{~mol} \mathrm{Tm}^{3+}$. This method solved the quenching effect using a high-power 

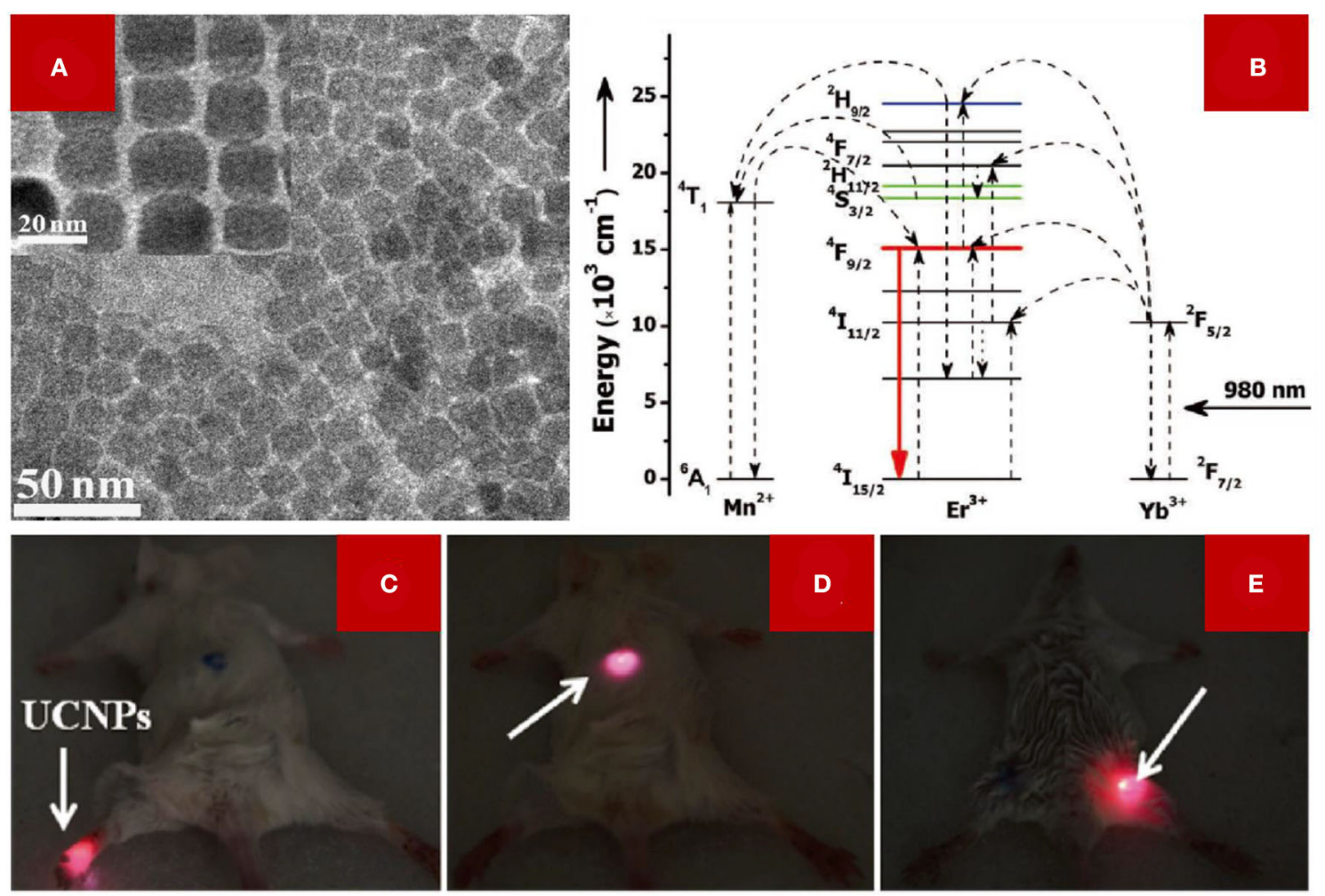

FIGURE 4 | (A) The TEM image (inset: HRTEM image) of NaYF 4 :Er,Yb NCs doped with 30 mol\% Mn²+ ions. (B) Schematic illustration of the mechanism of single red emission of $\mathrm{Mn}^{2+}$-doped $\mathrm{NaYF}_{4}$ : Yb/Er NCs. (C-E) Small animal imaging of Kunming mouse with irradiation of a $980 \mathrm{~nm}$ laser. The arrow indicates the injected site of the LDNCs dispersion. (A-E) were adopted from Tian et al. (2012).

pump up to $2.510^{6} \mathrm{~W} / \mathrm{cm}^{2}$. The quenching effect is mainly caused by the cross-relaxation of the ${ }^{1} \mathrm{G}_{4}$ to ${ }^{3} \mathrm{H}_{4}$ and ${ }^{3} \mathrm{H}_{6}$ to ${ }^{3} \mathrm{H}_{5}$ transitions, which usually occur under low-power irradiation (Figure 5B). For the high-power laser, the ${ }^{3} \mathrm{H}_{4}$ energy level is more likely to be promoted to a higher level, which leads to the absence of cross-relaxation and the enhanced upconversion emission intensity as well. Other similar results were illustrated, like the high doping level of $\mathrm{Yb}^{3+}$, to enhance the luminescence of a sub $10 \mathrm{~nm}$ matrix, and the authors claimed that the enhanced upconversion emission intensity was endorsed by the energy transfer from $\mathrm{Yb}^{3+}$ to $\mathrm{Tm}^{3+}$ (Zhai et al., 2014).

In addition, the overlap between the energy levels of different rare earth ions was studied. Cheng et al. (2018) demonstrated an energy level overlap of $\mathrm{Er}^{3+}$ and $\mathrm{Ho}^{3+}$, which lead to enhanced upconversion luminescence. Figures 5C,D show the TEM images of different concentrations of $\mathrm{Ho}^{3+}$-doped $\mathrm{NaYF}_{4}: \mathrm{Yb}, \mathrm{Er}$. Because of the similar ion sizes of $\mathrm{Er}^{3+}$ and $\mathrm{Ho}^{3+}$, the host lattice manipulation should be excluded. Under excitation at $1,532 \mathrm{~nm}$ (the energy can only be absorbed by $\mathrm{Er}^{3+}$ ), part of the energy is accumulated at the ${ }^{2} \mathrm{H}_{11 / 2}$ and ${ }^{4} \mathrm{~F}_{9 / 2}$ energy levels of the over-doped $\mathrm{Er}^{3+}$ ion, then the energy could be transferred to the ${ }^{5} \mathrm{~F}_{4} /{ }^{5} \mathrm{~S}_{2}$ and ${ }^{5} \mathrm{~F}_{5}$ energy levels of the codoped $\mathrm{Ho}^{3+}$ ions. Then the emissions at 544/550 and $648 \mathrm{~nm}$, which are produced by $\mathrm{Ho}^{3+}$, overlapped with the emissions of $\mathrm{Er}^{3+}$ at 525/545 and $660 \mathrm{~nm}$ (Figures 5F,G). Therefore, the enhanced upconversion emissions of $\mathrm{Er}^{3+}$ and $\mathrm{Ho}^{3+}$ co-doped nanocrystals can be ascribed to the dual contribution from both $\mathrm{Ho}^{3+}$ and $\mathrm{Er}^{3+}$ ions.

As for the downshifting luminescence of lanthanide ions, the gadolinium-based host lattice has been widely studied due to its optically active $\mathrm{Gd}^{3+}$ sublattices (Wang F. et al., 2007). The energy transfer between $\mathrm{Ce}^{3+}$ and $\mathrm{Ln}^{3+}(\mathrm{Ln}=\mathrm{Tb}, \mathrm{Eu}, \mathrm{Sm}$, or Dy) can be quickly achieved by a $\mathrm{Gd}^{3+}$ sublattice over a long distance. One of the benefits that the $\mathrm{Gd}^{3+}$ sublattice affords is that migrating energy can be trapped at a rather low doping concentration. Also, $\mathrm{Gd}^{3+}$ can act as an intermediary state to solve electron transfer quenching like the energy transfer from $\mathrm{Ce}^{3+}$ to $\mathrm{Eu}^{3+}$ (Wang F. et al., 2007). $\mathrm{Ce}^{3+}$ can also promote the energy transfer between activators and sensitizers. In 2019, Li et al. (2019) reported an enhanced downshifting emission located at $\sim 1,525 \mathrm{~nm}$ by doping $\mathrm{Ce}^{3+}$ into $\mathrm{NaLuF}_{4}: \mathrm{Gd} / \mathrm{Yb} / \mathrm{Er}$ nanorods. The $\sim 1,525 \mathrm{~nm}$ second near-infrared (NIR-II) emission was produced from the electronic transition between the excited state ${ }^{4} \mathrm{I}_{13 / 2}$ to ${ }^{4} \mathrm{I}_{15 / 2}$ of $\mathrm{Er}^{3+}$. However, the energy gap between the ground state ${ }^{2} \mathrm{~F}_{5 / 2}$ and the excited state ${ }^{2} \mathrm{~F}_{7 / 2}$ of $\mathrm{Ce}^{3+}$ matches well with the energy difference between the electronic transition of ${ }^{4} \mathrm{I}_{11 / 2} \rightarrow{ }^{4} \mathrm{I}_{13 / 2}$ of $\mathrm{Er}^{3+}$. The excited state ${ }^{4} \mathrm{I}_{11 / 2}$ of $\mathrm{Er}^{3+}$ could suffer an efficient non-radiative phonon-assisted cross-relaxation process, resulting in the significantly accumulated excited state ${ }^{4} \mathrm{I}_{13 / 2}$ of $\mathrm{Er}^{3+}$. Therefore, the electronic transition of ${ }^{4} \mathrm{I}_{13 / 2}$ 

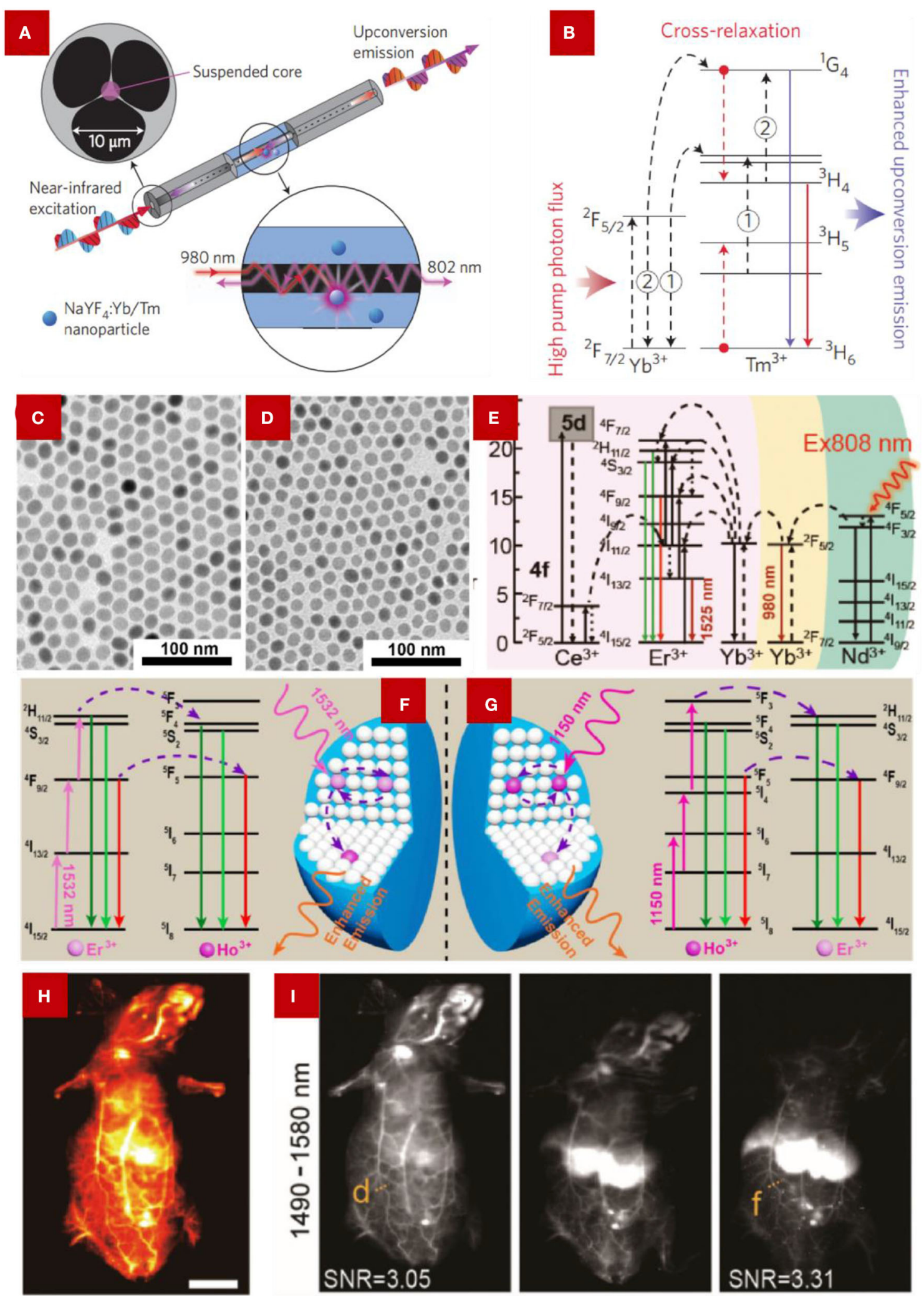

FIGURE 5 | (A) Schematic illustration of the integrated system with the micro-structured optical fiber with NaYF $\mathrm{F}_{4}: \mathrm{Yb}_{\mathrm{T}} \mathrm{Tm}$ nanoparticles and (B) the simplified mechanism of the energy transfer between $\mathrm{Yb}^{3+}$ and $\mathrm{Tm}^{3+}$ under $980 \mathrm{~nm}$ excitation, 1 and 2 represent two subsequent energy-transfer processes from $\mathrm{Yb}^{3+}$ to 
FIGURE 5 | Tm ${ }^{3+}$ ions. From Zhang and Liu (2013). TEM images of (C) NaYF 4 :Er/Ho (10/0.2 mol\%) NCs, (D) NaYF $:$ Er/Ho (10/1 mol\%) NCs. (C,D) were adopted from Cheng et al. (2018). (E) Schematic illustration of energy transfer in $\mathrm{Ce}^{3+}$-doped NaYbF $4: C e, E r ~ N C s$ for boosting the $\sim 1,525 \mathrm{~nm}$ emission. (C) were adopted from Cao et al. (2020). (F,G) Illustration of the scheme of the energy transfer process of $\mathrm{Er}^{3+}$ and $\mathrm{Ho}^{3+}$ under the irradiation of 1,532 and 1,150 nm, respectively. From Cheng et al. (2018). (H) Blood vessels imaging using NaYbF $4: E r, C e @ N a Y F_{4}: Y_{b} @ N a Y F_{4}: N d$ NCs. (I) NIR region luminescence collected from different time points (10 min, $4 \mathrm{~h}, 10 \mathrm{~h}$ ). The emission light was collected between the 1,490-1,580 $\mathrm{nm}$ regions, with the excitation of an $808 \mathrm{~nm}$ laser. (H,I) were adopted from Cao et al. (2020).

TABLE 1 | The summary of doping different metal ions into suitable host lattices and their possible mechanism for enhanced luminescence.

\begin{tabular}{|c|c|c|c|c|}
\hline Metal ions & Host lattice & Crystal phase & Synthesized methods & Possible mechanism \\
\hline \multirow[t]{8}{*}{$\mathrm{Li}^{+}$} & $\mathrm{ZrO}_{2}$ (Liu et al., 2011) & $\begin{array}{l}\text { Monoclinic phase } \\
\text { Tetragonal phase }\end{array}$ & Sol-gel process & Host lattice manipulation \\
\hline & $\mathrm{BaTiO}_{3}$ (Sun et al., 2011) & Cubic phase & Sol-gel process & \\
\hline & $\mathrm{Y}_{2} \mathrm{O}_{3}$ (Chen et al., 2008) & Cubic phase & - & \\
\hline & $\begin{array}{l}\mathrm{NaYF}_{4} \text { (Dou and Zhang, 2011; Zhao C. et al., } \\
\text { 2013) }\end{array}$ & Hexagonal phase & High temperature thermal-decomposition method & \\
\hline & $\mathrm{NaGdF}_{4}$ (Ding et al., 2015) & Hexagonal phase & Co-precipitation method & \\
\hline & $\mathrm{NaLuF}_{4}$ (Hu et al., 2017) & Hexagonal phase & Solvothermal method & \\
\hline & $\mathrm{TiO}_{2}$ (Cao et al., 2010) & $\begin{array}{l}\text { Anatase phase } \\
\text { Rutile phase }\end{array}$ & Sol-gel process & \\
\hline & $\mathrm{GdF}_{3}$ (Yin et al., 2012) & Orthorhombic phase & Hydrothermal procedure & \\
\hline \multirow[t]{3}{*}{$\mathrm{Fe}^{3+}$} & $\mathrm{NaBiF}_{4}$ (Du et al., 2019) & Hexagonal phase & Chemical precipitation method & $\begin{array}{l}\text { Host lattice manipulation, } \\
\text { energy transfer modulation }\end{array}$ \\
\hline & $\mathrm{NaGdF}_{4}$ (Ramasamy et al., 2013) & Hexagonal phase & High temperature thermal-decomposition method & \\
\hline & $\mathrm{NaYF}_{4}$ (Tang et al., 2015) & $\begin{array}{l}\text { Hexagonal phase } \\
\text { Cubic phase }\end{array}$ & Hydrothermal method & \\
\hline \multirow[t]{7}{*}{$\mathrm{Mn}^{2+}$} & $\mathrm{NaYF}_{4}$ (Tian et al., 2012; Zeng et al., 2014) & $\begin{array}{l}\text { Hexagonal phase } \\
\text { Cubic phase }\end{array}$ & Solvothermal method & $\begin{array}{l}\text { Host lattice manipulation, } \\
\text { energy transfer modulation }\end{array}$ \\
\hline & $\mathrm{NaLuF}_{4}$ (Zeng et al., 2014) & $\begin{array}{l}\text { Hexagonal phase } \\
\text { Cubic phase }\end{array}$ & Hydrothermal method & \\
\hline & $\mathrm{NaGdF}_{4}$ (Li et al., 2015) & Cubic phase & Thermal decomposition & \\
\hline & $\mathrm{NaYbF}_{4}$ (Zeng et al., 2014) & $\begin{array}{l}\text { Hexagonal phase } \\
\text { Cubic phase }\end{array}$ & Hydrothermal method & \\
\hline & $\mathrm{NaMnF}_{3}$ (Zhang et al., 2012) & Cubic phase & High temperature thermal-decomposition method & \\
\hline & $\mathrm{KMnF}_{3}$ (Ning et al., 2020) & Cubic phase & High temperature thermal-decomposition method & \\
\hline & $\mathrm{LiYF}_{4}$ (Zhou et al., 2018) & Tetragonal phase & Thermal decomposition & \\
\hline $\mathrm{Zn}^{2+}$ & $\mathrm{NaYbF}_{4}$ (Zhong et al., 2019) & Cubic phase & High temperature thermal-decomposition method & Host lattice manipulation \\
\hline $\mathrm{Ca}^{2+}$ & $\mathrm{NaYF}_{4}$ (Zhao et al., 2020) & $\begin{array}{l}\text { Cubic phase } \\
\text { Hexagonal phase }\end{array}$ & Co-precipitation method & Host lattice manipulation \\
\hline $\mathrm{Bi}^{3+}$ & $\mathrm{NaYF}_{4}$ (Niu et al., 2012) & $\begin{array}{l}\text { Cubic phase } \\
\text { Hexagonal phase }\end{array}$ & Facial microwave reflux method & Host lattice manipulation \\
\hline \multirow[t]{4}{*}{$\mathrm{Ce}^{3+}$} & $\mathrm{NaYF}_{4}$ (Li et al., 2019) & Hexagonal phase & Hydrothermal process & Energy transfer modulation \\
\hline & $\begin{array}{l}\mathrm{NaYbF}_{4} \text { (Zhong et al., 2017; Li et al., 2019; } \\
\text { Cao et al., 2020) }\end{array}$ & Cubic phase & Thermolysis method & \\
\hline & $\mathrm{NaLnF}_{4}$ (Li et al., 2019) & Hexagonal phase & Hydrothermal process & \\
\hline & $\mathrm{NaGdF}_{4}$ (Wang F. et al., 2007; Li et al., 2019) & Hexagonal phase & Hydrothermal process & \\
\hline \multirow[t]{2}{*}{$\mathrm{Eu}^{3+}$} & $\mathrm{NaErF}_{4}$ (Shang et al., 2018) & Hexagonal phase & High-temperature co-precipitation method & Energy transfer modulation \\
\hline & $\mathrm{NaGd}\left(\mathrm{MoO}_{4}\right)_{2}$ (Chen et al., 2020) & Tetragonal phase & Solid-state reaction method & \\
\hline $\mathrm{Tb}^{3+}$ & $\mathrm{NaYbF}_{4}$ (Zhou B. et al., 2015) & Hexagonal phase & Co-precipitation method & Energy transfer modulation \\
\hline \multirow[t]{2}{*}{$\mathrm{Ho}^{3+}$} & $\mathrm{NaYF}_{4}$ (Cheng et al., 2018) & Hexagonal phase & High-temperature co-precipitation method & Energy transfer modulation \\
\hline & $\mathrm{LiYF}_{4}$ (Cheng et al., 2018) & Hexagonal phase & High-temperature co-precipitation method & \\
\hline $\mathrm{Sc}^{3+}$ & $\mathrm{NaYF}_{4}$ (Huang et al., 2010) & Hexagonal phase & Hydrothermal method & Energy transfer modulation \\
\hline $\mathrm{Tm}^{3+}$ & $\begin{array}{l}\mathrm{NaErF}_{4} \text { (Chen et al., 2017; Shang et al., 2018; } \\
\text { Zhang et al., 2019) }\end{array}$ & Hexagonal phase & High-temperature co-precipitation method & Energy transfer modulation \\
\hline
\end{tabular}


$\rightarrow{ }^{4} \mathrm{I}_{15 / 2}$ of $\mathrm{Er}^{3+}$ is also promoted, which helps enhance the $\sim 1,525 \mathrm{~nm}$ emission intensity (Figure 5E). Cao et al. (2020) reported a similar result when they synthesized a core-shell structure of $\mathrm{NCs}_{1} \mathrm{NaYbF}_{4}: \mathrm{Er}, \mathrm{Ce} @ \mathrm{NaYF}_{4}: \mathrm{Yb} @ \mathrm{NaYF}_{4}: \mathrm{Nd}$. Under $808 \mathrm{~nm}$ excitation, the $\mathrm{NaYbF}_{4}: \mathrm{Er}, \mathrm{Ce} @ \mathrm{NaYF}_{4}: \mathrm{Yb} @ \mathrm{NaYF}_{4}: \mathrm{Nd}$ NCs showed a 10 times luminescence enhancement at $1525 \mathrm{~nm}$ than the NCs without doping $\mathrm{Ce}^{3+}$. As the light in the NIR-II window affords a superior signal to noise ratio and lower autofluorescence than the light in the first NIR window, the NIR-II emission gets increasing attention in deep tissue imaging. In Figures $\mathbf{5 H} \mathbf{H}$, the blood vessels can be clearly observed by using the $\mathrm{NaYbF}_{4}: \mathrm{Er}, \mathrm{Ce} @ \mathrm{NaYF}_{4}: \mathrm{Yb} @ \mathrm{NaYF}_{4}: \mathrm{Nd}$ $\mathrm{NCs}$, and the resolution can remain up to $0.25 \mathrm{~mm}$ even $10 \mathrm{~h}$ after the injection. Therefore, these excellent properties provide a potential application for LDNCs in the bioimaging fields.

\section{SUMMERY AND PERSPECTIVES}

Through summarizing the recent studies on how to improve the luminescence of LDNCs, breakthroughs have been made in some aspects. In this review, we summarize the recently reported methods on how to boost the upconversion and even downshift luminescence by doping metal ions, and introduce the related two mechanisms of doping in detail (Table 1).

Through the manipulation of the host lattice, the metal ions play a significant role in increasing the asymmetry around the lanthanides, therefore, leading to the increase of dipole transition. And for the energy transfer modulation, metal ions improve the overall energy transfer efficiency and decrease the quenching effect by providing an effective pathway in the process of energy transfer.

On the basis of improving emission intensity, some problems, still have not been explained clearly. For example, when introducing metal ions into the main lattice, especially for the mechanism of energy transfer regulation, the influence of the host lattice manipulation should not be ignored, which may disrupt the accuracy of the results. To resolve this effect, it can only be reduced by introducing metal ions with a small difference in the ion radius between the doping and occupied ions. And for ions like $\mathrm{Fe}^{3+}$, the enhancement of luminescence is the result of the combination of the two mechanisms. At the same time, how

\section{REFERENCES}

Auzel, F. O. (2004). Upconversion and anti-stokes processes with $\mathrm{f}$ and $\mathrm{d}$ ions in solids. Chem. Rev. 104, 139-173. doi: 10.1021/cr020357g

Beija, M., Afonso, C. A. M., and Martinho, J. M. G. (2009). Synthesis and applications of Rhodamine derivatives as fluorescent probes. Chem. Soc. Rev. 38, 2410-33. doi: 10.1039/b901612k

Ben, N. G., Adams, S. R., Mark Ellisman, H., and Roger Tsien, Y. (2006). The fluorescent toolbox for assessing protein location and function. Science 312, 217-224. doi: 10.1126/science. 1124618

Bünzli, J.-C. G. (2010). Lanthanide luminescence for biomedical analyses and imaging. Chem. Rev. 110, 2729-2755. doi: 10.1021/cr900362e

Cao, B. S., Feng, Z. Q., He, Y. Y., Li, H., and Dong, B. (2010). Opposite effect of $\mathrm{Li}^{+}$codoping on the upconversion emissions of $\mathrm{Er}^{3+}$-doped the metal ion is doped into the host lattice has not been fully explained. Site occupation or lattice filling might both exist in the same host lattice, and the method of metal ion doping has a relatively close relationship with the concentration and radius of the doping ions.

With further exploration of the research, the importance of the NIR-II light also shows itself. For deeper penetration, higher signal-to-noise ratio, and smaller scattering effect, the NIR-II light arouses increasing attention. Therefore, a rapidly growing number of recent studies have focused on improving near infrared luminescence, such as the emission of $\mathrm{Er}^{3+}$ at $\sim 1,530 \mathrm{~nm}$. The application of $\mathrm{Er}^{3+}$ in biological imaging is worth exploring. In addition, the enhancement of a certain emission band which was caused by non-radiative transition between two or more different rare earth ions is also the main focus of future research. It is necessary to develop more non-radiative transitions between different rare earth ions with good energy level matching to enhance the desired emission intensity. For now, most studies on the enhanced luminescence have been applied in the biological field, such as bioimaging and biosensing. There are some other applications that have been explored for the broader use of enhanced luminescence, such as anti-counterfeiting (Ding et al., 2020) and finger print latency (Wang et al., 2020), which endorse the importance of enhancing luminescence. Nonetheless, we believe that the rare earth ion-doped upconversion nanomaterials will have a wider range of applications and bright prospects in basic studies and technology fields.

\section{AUTHOR CONTRIBUTIONS}

SP collected and read papers, and wrote the draft manuscript. XG and LS outlined the main text content, discussed, and revised the manuscript. All authors contributed to the article and approved the submitted version.

\section{FUNDING}

We are grateful for the financial support from the National Natural Science Foundation of China (Grant No. 51872183) and Shuguang scholar of the Shanghai Municipal Education Commission (19SG38).
$\mathrm{TiO}_{2}$ powders. J. Sol. Gel Sci. Technol. 54, 101-104. doi: 10.1007/s10971-01 0-2163-3

Cao, C., Wu, N., Yuan, W., Gu, Y., Ke, J., Feng, W., et al. (2020). Ln(3+)-doped nanoparticles with enhanced NIR-II luminescence for lighting up blood vessels in mice. Nanoscale 12, 8248-8254. doi: 10.1039/D0NR01098G

Chen, G., Liu, H., Liang, H., Somesfalean, G., and Zhang, Z. (2008). Upconversion emission enhancement in $\mathrm{Yb}^{3+} \mathrm{Er}^{3+}$-codoped $\mathrm{Y}_{2} \mathrm{O}_{3}$ nanocrystals by tridoping with $\mathrm{Li}^{+}$ions. J. Phys. Chem. C 112, 12030-12036. doi: 10.1021/jp804064g

Chen, H., Ai, S., Dong, C., Wang, H., Ning, Z., Liu, M., et al. (2020). Eu ${ }^{3+}$-induced multicolor luminescence properties and enhanced thermal stability in the novel phosphors of $\mathrm{Li}_{0.1} \mathrm{Na}_{0.9} \mathrm{Gd}_{0.5} \mathrm{~Tb}_{0.5-\mathrm{x}} \mathrm{Eux}\left(\mathrm{MoO}_{4}\right)_{2}$. J. Lumin. 222:117116. doi: 10.1016/j.jlumin.2020.117116

Chen, Q., Xie, X., Huang, B., Liang, L., Han, S., Yi, Z., et al. (2017). Confining excitation energy in $\operatorname{Er}(3+)$-sensitized upconversion nanocrystals through 
$\operatorname{Tm}(3+)$-mediated transient energy trapping. Angew. Chem. Int. Ed. 56, 7605-7609. doi: 10.1002/anie.201703012

Chen, X., Peng, D., Ju, Q., and Wang, F. (2015). Photon upconversion in core-shell nanoparticles. Chem. Soc. Rev. 44, 1318-1330. doi: 10.1039/C4CS00151F

Cheng, X., Ge, H., Wei, Y., Zhang, K., Su, W., Zhou, J., et al. (2018). Design for brighter photon upconversion emissions via energy level overlap of lanthanide ions. ACS Nano 12, 10992-10999. doi: 10.1021/acsnano.8b04988

Ding, M., Dong, B., Lu, Y., Yang, X., Yuan, Y., Bai, W., et al. (2020). Energy manipulation in lanthanide-doped core-shell nanoparticles for tunable dual-mode luminescence toward advanced anti-counterfeiting. Adv. Mater. 2020:2002121. doi: 10.1002/adma.202002121

Ding, M., Ni, Y., Song, Y., Liu, X., Cui, T., Chen, D., et al. (2015). Li + ions doping core-shell nanostructures: an approach to significantly enhance upconversion luminescence of lanthanide-doped nanocrystals. J. Alloy. Compd. 623, 42-48. doi: 10.1016/j.jallcom.2014.10.089

Dou, Q., and Zhang, Y. (2011). Tuning of the structure and emission spectra of upconversion nanocrystals by alkali ion doping. Langmuir 27, 13236-13241. doi: 10.1021/la201910t

Du, P., Zhang, Q., Wang, X., Luo, L., and Li, W. (2019). Upconversion luminescence, temperature sensing and internal heating behaviors of $\mathrm{Er}^{3+} / \mathrm{Yb}^{3+} / \mathrm{Fe}^{3+}$-tridoped $\mathrm{NaBiF}_{4}$ nanoparticles. J. Alloy. Compd. 805, 171-179. doi: 10.1016/j.jallcom.2019.07.054

Fan, Y., Wang, P., Lu, Y., Wang, R., Zhou, L., Zheng, X., et al. (2018). Lifetimeengineered NIR-II nanoparticles unlock multiplexed in vivo imaging. Nat. Nanotechnol. 13, 941-946. doi: 10.1038/s41565-018-0221-0

Fan, Y., and Zhang, F. (2019). A new generation of NIR-II probes: lanthanidebased nanocrystals for bioimaging and biosensing. Adv. Opt. Mater. 7:1801417. doi: 10.1002/adom.201801417

Han, S., Deng, R., Xie, X., and Liu, X. (2014). Enhancing luminescence in lanthanide-doped upconversion nanoparticles. Angew. Chem. Int. Ed. 53, 11702-11715. doi: 10.1002/anie.201403408

Harris, D. C., and Bertolucci, M. D. (1978). Symmetry and Spectroscopy. New York, NY: Oxford University Press.

Hatanaka, M., and Yabushita, S. (2014). Mechanisms of f-f hypersensitive transition intensities of lanthanide trihalide molecules: a spinorbit configuration interaction study. Theor. Chem. Acc. 133:1517. doi: $10.1007 / \mathrm{s} 00214-014-1517-2$

Hazra, C., Ullah, S., Serge Correales, Y. E., Caetano, L. G., and Ribeiro, S. J. L. (2018). Enhanced NIR-I emission from water-dispersible NIR-II dye-sensitized core/active shell upconverting nanoparticles. J. Mate. Chem. C 6, 4777-4785. doi: 10.1039/C8TC00335A

Hildebrandt, N., Spillmann, C. M., Algar, W. R., Pons, T., Stewart, M. H., Oh, E., et al. (2017). Energy transfer with semiconductor quantum dot bioconjugates: a versatile platform for biosensing, energy harvesting, and other developing applications. Chem. Rev. 117, 536-711. doi: 10.1021/acs.chemrev.6b00030

Hu, M., Ma, D., Cheng, Y., Liu, C., Zhang, Z., Cai, Y., et al. (2017). Synergistically enhanced upconversion luminescence in $\mathrm{Li}(+)$-doped core-shell-structured ultrasmall nanoprobes for dual-mode deep tissue fluorescence/CT imaging. J. Mater. Chem. B 5, 2662-2670. doi: 10.1039/C6TB02976K

Huang, Q., Yu, J., Ma, E., and Lin, K. (2010). Synthesis and characterization of highly efficient near-infrared upconversion $\mathrm{Sc}^{3+} / \mathrm{Er}^{3+} / \mathrm{Yb}^{3+}$ tridoped $\mathrm{NaYF}_{4}$. J. Phys. Chem. C 4719-4724. doi: 10.1021/jp908645h

Jiang, L., Xiao, S., Yang, X., Ding, J., and Dong, K. (2012). Enhancement of upconversion luminescence in $\mathrm{Zn}_{2} \mathrm{SiO}_{4}: \mathrm{Yb}^{3+}, \mathrm{Er}^{3+}$ by co-doping with $\mathrm{Li}^{+}$or $\mathrm{Bi}^{3+}$. Appl. Phys. B 107, 477-481. doi: 10.1007/s00340-012-4986-9

Kobayashi, H., Kosaka, N., Ogawa, M., Morgan, N. Y., Smith, P. D., Murray, C. B., et al. (2009). In vivo multiple color lymphatic imaging using upconverting nanocrystals. J. Mater. Chem. 19:6481. doi: 10.1039/b910512c

Li, X., Liu, X., Chevrier, D. M., Qin, X., Xie, X., Song, S., et al. (2015). Energy migration upconversion in manganese(II)-doped nanoparticles. Angew. Chem. Int. Ed. 54, 13312-13317. doi: 10.1002/anie.201507176

Li, Y., Zeng, S., and Hao, J. (2019). Non-invasive optical guided tumor metastasis/vessel imaging by using lanthanide nanoprobe with enhanced down-shifting emission beyond $1500 \mathrm{~nm}$. ACS Nano 13, 248-259. doi: 10.1021/acsnano.8b05431

Liu, L., Wang, Y., Zhang, X., Yang, K., Bai, Y., Huang, C., et al. (2011). Efficient two-color luminescence of $\mathrm{Er}^{3+} / \mathrm{Yb}^{3+} / \mathrm{Li}^{+}: \mathrm{ZrO}_{2}$ nanocrystals. Opt. Mater. 33, 1234-1238. doi: 10.1016/j.optmat.2011.02.019
Ning, H., Jing, L., Hou, Y., Kalytchuk, S., Li, Y., Huang, X., et al. (2020). Manganese-mediated growth of $\mathrm{ZnS}$ shell on $\mathrm{KMnF}_{3}: \mathrm{Yb}$, Er cores toward enhanced up/downconversion luminescence. ACS Appl. Mater. Inter. 12, 11934-11944. doi: 10.1021/acsami.9b21832

Niu, N., He, F., Gai, S., Li, C., Zhang, X., Huang, S., et al. (2012). Rapid microwave reflux process for the synthesis of pure hexagonal $\mathrm{NaYF}_{4}: \mathrm{Yb}^{3+}, \mathrm{Ln}^{3+}, \mathrm{Bi}^{3+}$ $\left(\mathrm{Ln}^{3+}=\mathrm{Er}^{3+}, \mathrm{Tm}^{3+}, \mathrm{Ho}^{3+}\right)$ and its enhanced UC luminescence. J. Mater. Chem. 22:21613. doi: 10.1039/c2jm34653b

Qin, W.-P., Liu, Z.-Y., Sin, C.-N., Wu, C.-F., Qin, G.-S., Chen, Z., et al. (2014). Multi-ion cooperative processes in $\mathrm{Yb}^{3+}$ clusters. Light Sci. Appl. 3:e193. doi: 10.1038/lsa.2014.74

Qin, X., Xu, J., Wu, Y., and Liu, X. (2019). Energy-transfer editing in lanthanideactivated upconversion nanocrystals: a toolbox for emerging applications. ACS Cent. Sci. 5, 29-42. doi: 10.1021/acscentsci.8b00827

Ramasamy, P., Chandra, P., Rhee, S. W., and Kim, J. (2013). Enhanced upconversion luminescence in $\mathrm{NaGdF}_{4}: \mathrm{Yb}, \mathrm{Er}$ nanocrystals by $\mathrm{Fe}^{3+}$ doping and their application in bioimaging. Nanoscale 5, 8711-8717. doi: $10.1039 / \mathrm{c} 3 \mathrm{nr} 01608 \mathrm{k}$

Shang, Y., Hao, S., Lv, W., Chen, T., Tian, L., Lei, Z., et al. (2018). Confining excitation energy of $\mathrm{Er}^{3+}$-sensitized upconversion nanoparticles through introducing various energy trapping centers. J. Mater. Chem. C 6, 3869-3875. doi: 10.1039/C7TC05742C

Su, Q., Feng, W., Yang, D., and Li, F. (2017). Resonance energy transfer in upconversion nanoplatforms for selective biodetection. Acc. Chem. Res. 50, 32-40. doi: 10.1021/acs.accounts.6b00382

Sun, Q., Chen, X., Liu, Z., Wang, F., Jiang, Z., and Wang, C. (2011). Enhancement of the upconversion luminescence intensity in $\mathrm{Er}^{3+}$ doped $\mathrm{BaTiO}_{3}$ nanocrystals by codoping with $\mathrm{Li}^{+}$ions. J. Alloy. Compd. 509, 5336-5340. doi: 10.1016/j.jallcom.2010.12.212

Tang, J., Chen, L., Li, J., Wang, Z., Zhang, J., Zhang, L., et al. (2015). Selectively enhanced red upconversion luminescence and phase/size manipulation via $\mathrm{Fe}(3+)$ doping in $\mathrm{NaYF}_{4}: \mathrm{Yb}$,Er nanocrystals. Nanoscale 7, 14752-14759. doi: $10.1039 / C 5 N R 04125 B$

Terai, T., and Nagano, T. (2008). Fluorescent probes for bioimaging applications. Curr. Opin. Chem. Biol. 12, 515-521. doi: 10.1016/j.cbpa.2008.08.007

Tian, G., Gu, Z., Zhou, L., Yin, W., Liu, X., Yan, L., et al. (2012). $\mathrm{Mn}^{2+}$ dopant-controlled synthesis of $\mathrm{NaYF}_{4}: \mathrm{Yb} / \mathrm{Er}$ upconversion nanoparticles for in vivo imaging and drug delivery. Adv. Mater. 24, 1226-1231. doi: 10.1002/adma.201104741

Wang, F., Deng, R., Wang, J., Wang, Q., Han, Y., Zhu, H., et al. (2011). Tuning upconversion through energy migration in core-shell nanoparticles. Nat. Mater. 10, 968-973. doi: $10.1038 /$ nmat3149

Wang, F., Fan, X., Wang, M., and Zhang, Y. (2007). Multicolour $\mathrm{PEI} / \mathrm{NaGdF}_{4}: \mathrm{Ce}^{3+}, \mathrm{Ln}^{3+}$ nanocrystals by single-wavelength excitation. Nanotechnology 18:025701. doi: 10.1088/0957-4484/18/2/025701

Wang, J., Deng, R., MacDonald, M. A., Chen, B., Yuan, J., Wang, F., et al. (2014). Enhancing multiphoton upconversion through energy clustering at sublattice level. Nat. Mater. 13, 157-162. doi: 10.1038/nmat3804

Wang, J., Wang, F., Wang, C., Liu, Z., and Liu, X. (2011). Single-band upconversion emission in lanthanide-doped $\mathrm{KMnF}_{3}$ nanocrystals. Angew. Chem. Int. Ed. 50, 10369-10372. doi: 10.1002/anie.201104192

Wang, X., Yan, L., Liu, S., Zhang, P., Huang, R., and Zhou, B. (2020). Enhancing energy migration upconversion through a migratory interlayer in the core-shell-shell nanostructure towards latent fingerprinting. Nanoscale 12, 18807-18814. doi: 10.1039/D0NR03817B

Wang, Y., Wei, T., Cheng, X., Ma, H., Pan, Y., Xie, J., et al. (2017). Insights into $\mathrm{Li}^{+}$-induced morphology evolution and upconversion luminescence enhancement of $\mathrm{KSc}_{2} \mathrm{~F}_{7}: \mathrm{Yb} / \mathrm{Er}$ nanocrystals. J. Mater. Chem. C 5, 3503-3508. doi: $10.1039 /$ C7TC00649G

Weissleder, R., and Pittet, M. J. (2008). Imaging in the era of molecular oncology. Nature 452, 580-589. doi: 10.1038/nature06917

Wu, M., Song, E. H., Chen, Z. T., Ding, S., Ye, S., Zhou, J. J., et al. (2016). Single-band red upconversion luminescence of $\mathrm{Yb}^{3+}-\mathrm{Er}^{3+}$ via nonequivalent substitution in perovskite $\mathrm{KMgF}_{3}$ nanocrystals. J. Mater. Chem. C 4, 1675-1684. doi: 10.1039/C5TC03600C

Wu, X., Zhang, Y., Takle, K., Bilsel, O., Li, Z., Lee, H., et al. (2016). Dye-sensitized core/active shell upconversion nanoparticles for optogenetics and bioimaging applications. ACS Nano 10, 1060-1066. doi: 10.1021/acsnano.5b06383 
Xu, G., Zeng, S., Zhang, B., Swihart, M. T., Yong, K. T., and Prasad, P. N. (2016). New generation cadmium-free quantum dots for biophotonics and nanomedicine. Chem. Rev. 116, 12234-12327. doi: 10.1021/acs.chemrev.6b00290

Yin, W., Zhao, L., Zhou, L., Gu, Z., Liu, X., Tian, G., et al. (2012). Enhanced red emission from $\mathrm{GdF}_{3}: \mathrm{Yb}^{3+}, \mathrm{Er}^{3+}$ upconversion nanocrystals by $\mathrm{Li}^{+}$ doping and their application for bioimaging. Chemistry 18, 9239-9245. doi: $10.1002 /$ chem.201201053

Yin, Z., Li, H., Xu, W., Cui, S., Zhou, D., Chen, X., et al. (2016). Local field modulation induced three-order upconversion enhancement: combining surface plasmon effect and photonic crystal effect. Adv. Mater. 28, 2518-2525. doi: 10.1002/adma.201502943

Yuan, L., Lin, W., Zheng, K., He, L., and Huang, W. (2013). Far-red to near infrared analyte-responsive fluorescent probes based on organic fluorophore platforms for fluorescence imaging. Chem. Soc. Rev. 42, 622-661. doi: 10.1039/C2CS35313J

Zeng, S., Yi, Z., Lu, W., Qian, C., Wang, H., Rao, L., et al. (2014). Simultaneous realization of phase/size manipulation, upconversion luminescence enhancement, and blood vessel imaging in multifunctional nanoprobes through transition metal $\mathrm{Mn}^{2+}$ doping. Adv. Funct. Mater. 24, 4051-4059. doi: 10.1002/adfm.201304270

Zhai, X., Liu, S., Zhang, Y., Qin, G., and Qin, W. (2014). Controlled synthesis of ultrasmall hexagonal $\mathrm{NaTm}_{0.02} \mathrm{Lu}_{0.98-\mathrm{x}} \mathrm{Yb}_{\mathrm{x}} \mathrm{F}_{4}$ nanocrystals with enhanced upconversion luminescence. J. Mater. Chem. C 2:2037. doi: 10.1039/c3tc31760a

Zhang, H., Fan, Y., Pei, P., Sun, C., Lu, L., and Zhang, F. (2019). Tm(3+) sensitized NIR-II fluorescent nanocrystals for in vivo information storage and decoding. Angew. Chem. Int. Ed. 58, 10153-10157. doi: 10.1002/anie.201903536

Zhang, H., Li, Y., Ivanov, I. A., Qu, Y., Huang, Y., and Duan, X. (2010). Plasmonic modulation of the upconversion fluorescence in $\mathrm{NaYF}_{4}: \mathrm{Yb} / \mathrm{Tm}$ hexaplate nanocrystals using gold nanoparticles or nanoshells. Angew. Chem. Int. Ed. 49, 2865-2868. doi: 10.1002/anie.200905805

Zhang, Y., Lin, J. D., Vijayaragavan, V., Bhakoo, K. K., and Tan, T. T. (2012). Tuning sub-10 nm single-phase $\mathrm{NaMnF}_{3}$ nanocrystals as ultrasensitive hosts for pure intense fluorescence and excellent $\mathrm{T}_{1}$ magnetic resonance imaging. Chem. Commun. 48, 10322-10324. doi: 10.1039/c2cc34858f

Zhang, Y., and Liu, X. (2013). Nanocrystals: shining a light on upconversion. Nat. Nanotechnol. 8, 702-703. doi: 10.1038/nnano.2013.199

Zhao, C., Kong, X., Liu, X., Tu, L., Wu, F., Zhang, Y., et al. (2013). Li ${ }^{+}$ ion doping: an approach for improving the crystallinity and upconversion emissions of $\mathrm{NaYF}_{4}: \mathrm{Yb}^{3+}, \mathrm{Tm}^{3+}$ nanoparticles. Nanoscale 5, 8084-8089. doi: $10.1039 / \mathrm{c} 3 \mathrm{nr} 01916 \mathrm{k}$

Zhao, J., Hu, Y., Lin, S. W., Resch-Genger, U., Zhang, R., Wen, J., et al. (2020). Enhanced luminescence intensity of near-infrared-sensitized upconversion nanoparticles via $\mathrm{Ca}^{2+}$ doping for a nitric oxide release platform. J. Mater. Chem. B. 2020, 6481-6489. doi: 10.1039/D0TB00088D

Zhao, J., Jin, D., Schartner, E. P., Lu, Y., Liu, Y., Zvyagin, A. V., et al. (2013). Singlenanocrystal sensitivity achieved by enhanced upconversion luminescence. Nat. Nanotechnol. 8, 729-734. doi: 10.1038/nnano.2013.171

Zhao, Q., Huang, C., and Li, F. (2011). Phosphorescent heavy-metal complexes for bioimaging. Chem. Soc. Rev. 40:2508. doi: 10.1039/c0cs00114g

Zhao, Q., Li, F., and Huang, C. (2010). Phosphorescent chemosensors based on heavy-metal complexes. Chem. Soc. Rev. 39, 3007-3030. doi: 10.1039/ b915340c

Zhong, Y., Ma, Z., Wang, F., Wang, X., Yang, Y., Liu, Y., et al. (2019). In vivo molecular imaging for immunotherapy using ultra-bright nearinfrared-IIb rare-earth nanoparticles. Nat. Biotechnol. 37, 1322-1331. doi: 10.1038/s41587-019-0262-4

Zhong, Y., Ma, Z., Zhu, S., Yue, J., Zhang, M., Antaris, A., et al. (2017). Boosting the down-shifting luminescence of rare-earth nanocrystals for biological imaging beyond $1500 \mathrm{~nm}$. Nat. Commun. 8:737. doi: 10.1038/s41467-017-00917-6

Zhou, B., Xu, B., He, H., Gu, Z., Tang, B., Ma, Y., et al. (2018). Enhanced green upconversion luminescence in tetrahedral $\mathrm{LiYF}_{4}: \mathrm{Yb} / \mathrm{Er}$ nanoparticles by manganese(ii)-doping: the key role of the host lattice. Nanoscale 10, 2834-2840. doi: 10.1039/C7NR07709B

Zhou, B., Yang, W., Han, S., Sun, Q., and Liu, X. (2015). Photon upconversion through $\mathrm{Tb}(3+)$-mediated interfacial energy transfer. Adv. Mater. 27 6208-6212. doi: 10.1002/adma.201503482

Zhou, J., Yang, Y., and Zhang, C. Y. (2015). Toward biocompatible semiconductor quantum dots: from biosynthesis and bioconjugation to biomedical application. Chem. Rev. 115, 11669-11717. doi: 10.1021/acs.chemrev.5b00049

Zhuo, Z., Liu, Y., Liu, D., Huang, P., Jiang, F., Chen, X., et al. (2017) Manipulating energy transfer in lanthanide-doped single nanoparticles for highly enhanced upconverting luminescence. Chem. Sci. 8, 5050-5056. doi: 10.1039/C7SC01393K

Conflict of Interest: The authors declare that the research was conducted in the absence of any commercial or financial relationships that could be construed as a potential conflict of interest.

Copyright (c) $2020 \mathrm{Pei}, \mathrm{Ge}$ and Sun. This is an open-access article distributed under the terms of the Creative Commons Attribution License (CC BY). The use, distribution or reproduction in other forums is permitted, provided the original author(s) and the copyright owner(s) are credited and that the original publication in this journal is cited, in accordance with accepted academic practice. No use, distribution or reproduction is permitted which does not comply with these terms. 